\title{
Takayasu's arteritis and cerebral venous thrombosis: comorbidity or coincidence?
}

\author{
Arterite de Takayasu e trombose venosa cerebral: comorbidade ou coincidência? \\ Ricardo de Carvalho Nogueira, Emanoela Faro de Oliveira, Adriana Bastos Conforto, Edson Bor-Seng-Shu, \\ Paulo Puglia, Leandro Tavares Lucato, Paulo Eurípedes Marchiori
}

Neurology Department of Hospital das Clínicas, Universidade de São Paulo (USP), São Paulo SP, Brazil.

Correspondence: Ricardo de Carvalho Nogueira; Departamento de Neurologia, Hospital das Clínicas, Universidade de São Paulo; Avenida Dr. Enéas de Carvalho Aguiar 255/5131;05403-000 São Paulo SP - Brasil; E-mail: rcnogueira28@ig.com.br

Conflict of interest: There is no conflict of interest to declare.

Received 15 December 2011; Received in final form 29 March 2012; Accepted 09 April 2012

Takayasu's Arteritis (TA) is an inflammatory disease that affects large blood vessels. The most common neurological features are headache, dizziness, syncope and visual blurring ${ }^{1}$. Symptoms often start in the second or third decade of life ${ }^{1,2}$, and diagnosis is made through clinical and radiological criteria ${ }^{1}$.

Cerebral Venous Trombosis (CVT) usually affects young patients, and the most common clinical presentation is severe headache with signals and symptoms of intracranial hypertension ${ }^{3}$.

The aim of this paper was to report an uncommon case with clinical and radiological findings of TA and CVT.

\section{CASE REPORT}

A 39-year old woman complained of leg cramps, weight loss, occipital headache and visual blurring. At the initial assessment, her brachial, femoral, popliteal and tibial pulses were diminished and asymmetric; the neuro-ophtalmic examination revealed papilledema and decreased visual acuity (20/100 bilaterally). Magnetic ressonance image (MRI) with magnetic ressonance venography revealed $\mathrm{T} 2$ and FLAIR hyperintense areas in the parietal and occipital regions, meningeal thickening and reduced lumen of the left transversal sinus (Fig 1), suggesting chronic cerebral venous thrombosis. Computerized Tomography Angiography (CTA) of the aorta and its main branches revealed diffuse arterial thickening (Fig 2).

The blood screening disclosed increased values of serum inflammatory markers: Erythrocyte Sedimentation Rate (ESR) of $94 \mathrm{~mm} / \mathrm{h}$ and C-reactive protein (CRP) of $44.8 \mathrm{mg} / \mathrm{dL}$; the cerebrospinal fluid sample had pleocytosis $\left(20\right.$ cells $/ \mathrm{mm}^{3}$; $64 \%$ lymphocyte), and the meningeal biopsy revealed chronic non-specific inflammatory cell infiltrate. Additional laboratorial investigation (lupus antibody, anti-cardiolipin antibody, $\mathrm{C}$ and S protein, homocystein, Leiden factor V, mutant prothrombin gene) excluded other thrombophilia. Treatment with

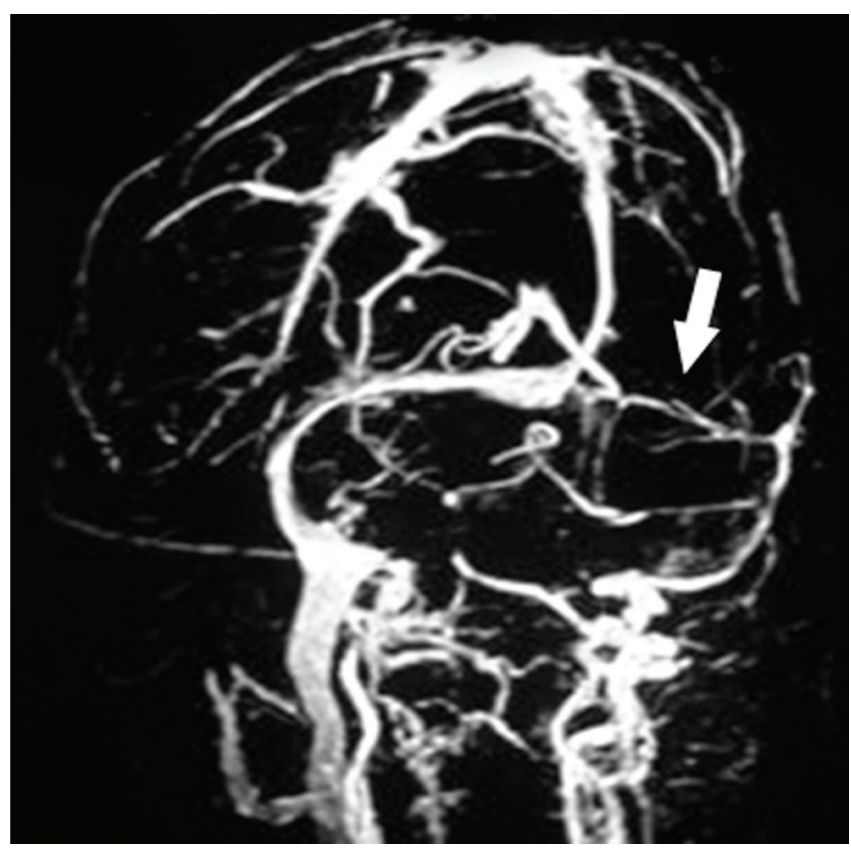

Fig 1. Magnetic ressonance venography showing narrowed lumen of the left transverse sinus (arrow).

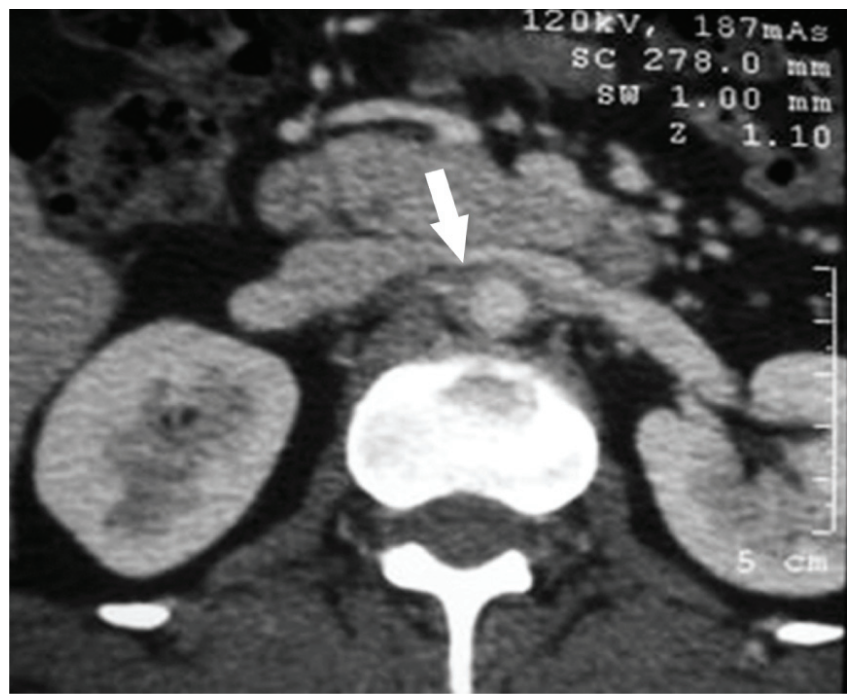

Fig 2. Computerized tomography angiography demonstrates wall thickening of abdominal aorta (arrow) suggesting vasculitis. 
anticoagulant medication was initiated, followed by prednisone. Visual complaints improved, and the serum inflammatory markers normalized.

\section{DISCUSSION}

The diagnostic criteria for TA are mainly clinical; nevertheless, laboratory analysis frequently reveals increased ESR and CRP. Although they are not gold standard, CTA and MRI are useful keys to diagnosis ${ }^{1,4}$. During the acute phase, inflammatory infiltration affects all layers of the arterial wall, whereas at the chronic phase fibrous tissue replaces the damaged layers and arterial stenosis may develop ${ }^{1,2}$. Differential diagnoses include other type of large vessel inflammatory vasculitis ${ }^{1}$.
CVT is a disease that also affects younger individuals; however, associated arterial thrombosis is identified in only $10 \%$ of the patients ${ }^{5}$. Whilst blood coagulation disorders are important causes of CVT, multiple factors may contribute as a precipitant of venous thrombosis ${ }^{5}$. Despite all the efforts to find its etiology, it remains unidentified in $20 \%$ of the patients ${ }^{3}$. Our patient fulfilled four of the six criteria for $\mathrm{TA}$, had radiological imaging suggestive of CVT and was extensively investigated to exclude other conditions.

CVT and TA have clinical similarities which are important to be remembered during the diagnostic work up ${ }^{3}$. Simultaneous presence of CVT and TA is unexpected and raises the possibility of either causal or casual association between these two conditions.

\section{References}

1. Johnston SL, Lock RJ, Gompels MM. Takayasu arteritis: a review.J Clin Pathol 2002;55:481-486.

2. Vanoli M, Daina E, Salvarani C, et al. Takayasu's arteritis: a study of 104 Italian patients. Arthritis Rheum 2005;53:100-107.

3. Stam J. Current Concepts: Thrombosis of the Cerebral Veins and Sinuses. N Eng J Med 2005;352:1791-1798.
Cantú C, Pineda C, Barinagarrementeria F, et al. Noninvasive cerebrovascular assessment of Takayasu arteritis. Stroke 2000;31:2197-2202

5. van Gijn J. Cerebral venous thrombosis: pathogenesis, presentation and prognosis. J R Soc Med 2000;93:230-233. 